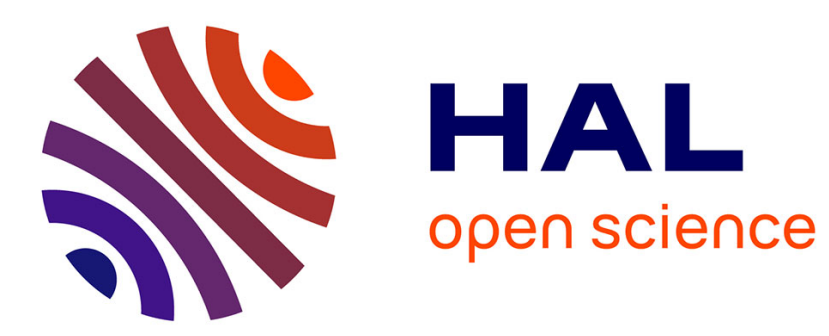

\title{
Catalytic electrochemical pre-treatment for the degradation of persistent organic pollutants
}

Florence Geneste

\section{To cite this version:}

Florence Geneste. Catalytic electrochemical pre-treatment for the degradation of persistent organic pollutants. Current Opinion in Electrochemistry, 2018, 11, pp.19-24. 10.1016/j.coelec.2018.07.002 . hal-01915485

HAL Id: hal-01915485

https://hal-univ-rennes1.archives-ouvertes.fr/hal-01915485

Submitted on 7 Nov 2018

HAL is a multi-disciplinary open access archive for the deposit and dissemination of scientific research documents, whether they are published or not. The documents may come from teaching and research institutions in France or abroad, or from public or private research centers.
L'archive ouverte pluridisciplinaire HAL, est destinée au dépôt et à la diffusion de documents scientifiques de niveau recherche, publiés ou non, émanant des établissements d'enseignement et de recherche français ou étrangers, des laboratoires publics ou privés. 


\section{Highlights}

- Improvement of biodegradability by catalytic electrochemical processes

- Coupling a catalytic electrochemical pre-treatment with a biological process for remediation

- Targeting specific functional groups to improve the biodegradability of persistent compounds

- Indirect electrolysis and electrocatalysis as selective and well-controlled pretreatments 
Catalytic electrochemical pre-treatment for the degradation of persistent organic pollutants

\section{F. Geneste*}

Univ Rennes, CNRS, ISCR (Institut des Sciences Chimiques de Rennes) - UMR 6226, F35000 Rennes, France.

Electrochemical advanced oxidation processes have been widely explored for the total degradation of biorecalcitrant compounds such as some pesticides and pharmaceuticals. More recently, coupling processes involving an electrochemical pre-treatment followed by a biological process have been proposed as cost-effective and reliable remediation methods for the mineralization of persistent compounds. This open the way to more selective electrochemical methods than those involving hydroxyl radicals since the aim of the pretreatment is no more to achieve the total mineralization of non-biodegradable species, but is only the improvement of their biodegradability focusing on functional groups known to reduce it. In this context, catalytic electrochemical reductions and oxidations can find their place in a coupling process for the remediation of biorecalcitrant compounds as selective and well-controlled methods. This review summarizes some relevant and recent work on catalytic electrochemical processes performed in aqueous medium that have been used to improve the biodegradability of persistent organic pollutants.

\section{Introduction}

Non-biodegradable compounds, among for example industrials chemicals, synthetic pharmaceuticals, dyes and pesticides tend to accumulate in the environment. Owning to their potential toxicity and carcinogenicity, physico-chemical treatments have been used for their remediation. Advanced oxidation processes (AOPs) have been widely investigated since they involve the formation of very reactive hydroxyl radicals that have a high standard redox potential (2.8 V/SHE) and thus are able to achieve total mineralization of species. Among them, electrochemical advanced oxidation processes (EAOPs) such as electrooxidation and electro-Fenton treatments present some advantages such as no requirement of chemical addition. However, despite their high efficiency, these methods suffer from high cost and low selectivity that can lead to the formation of toxic by-products if the mineralization is not complete. An interesting and cost-effective alternative is the coupling of a physico-chemical pre-treatment used only to increase the biodegradability of the compounds with a biological process that will achieve the total mineralization. Interestingly, the biodegradability of a substrate is highly dependent on its initial concentration and on its chemical structure. Thus, some functional groups such as halogen, nitro groups and aromatic rings are known to retard the biodegradation of species [1]. The role of the physico-chemical pre-treatment will be to specifically remove these groups or transform them into functions that are more easily assimilated by activated sludge. In this context, selective electrochemical processes, even if they are not efficient to achieve the total mineralization of biorecalcitrant compounds, can find their place as pre-treatment before a biological process for environmental remediation. Advantageously, since mineralization of species does not occur, by-products are expected to be used as carbon sources during the subsequent biological treatment. Concentrated effluents from for example industry, agriculture and hospitals can be expected to be treated by electrochemical methods. Thus, simple electrochemical oxidations of electroactive biorecalcitrant compounds on graphite felt electrodes have shown their efficiency to improve the biodegradability of phosmet, 2,4-dichlorophenoxyacetic acid and sulfamethazine [2-8], 
although it has been shown that no hydroxyl radicals were formed during the oxidation process [9].

Catalytic electrochemical processes have also been used to improve the biodegradability of persistent compounds, targeting a functional group suspected to reduce the biodegradability. In this overview, we aim to summarize catalytic electrochemical methods that would be relevant as pre-treatment before the implementation of a biological process aiming to achieve the total mineralization of biorecalcitrant compounds. Two different catalytic processes will be distinguished: indirect electrolysis that uses organometallic/molecular catalysts and electrocatalysis that involves metal electrodes.

\section{Indirect electrolysis}

Indirect electrolysis consists in the use of a redox catalyst (mediator) that allows the electron transfer to take place in homogeneous phase instead of heterogeneous phase [10]. It is particularly interesting as electrochemical pre-treatment, since it can perform redúctions and oxidations at higher and lower potentials, respectively, than in direct electrolysís, improving the current efficiencies and reducing the energy consumption. Higher and even different selectivities can be achieved compared with electrochemical reduction/oxidation on inert electrodes. However, for coupling the electrochemical process with a biological treatment, the catalyst does not have to be in the effluent to be treated owning first to its high cost and also because most of them are organometallic complexes that are rarely assimilable by microorganisms from activated sludge. Its immobilization on the electrode surface is usually envisaged since it presents also several advantages; hence, the catalyst is located at the interface, place of the electron transfer reactions and a good solubility of the catalyst in aqueous medium is not necessary.

Reductive dehalogenation reactions, especially dechlorination, have been the subject of many investigations since the presence of halogen atoms in a molecule is known to decrease its biodegradability. Advantageously, in opposite to anodic oxidation processes, there is no concern about the production of toxic polyhalogenated by-products formed by the oxidation of chloride ions with electrochemical reduction reactions. Furthermore, the recovery of the halogenated species in their ionic form, can be performed, that is of a particular interest for iodine compounds [11]. Many coordination complexes catalyzing the electrochemical reduction of halogenated compounds have been proposed in literature, although their catalytic activity towards the reduction of halogen bonds in aqueous medium has not always been demonstrated [12-15]. Among them, Ni(I)(cyclam) derivatives have shown a good catalytic activity towards the reduction of bromoacetic and benzoic acids, propargyloxy and allyloxy $\alpha$-bromoester, epichlorohydrin and 1,3-dichloropropane in hydroalcoholic and aqueous media [16-20].

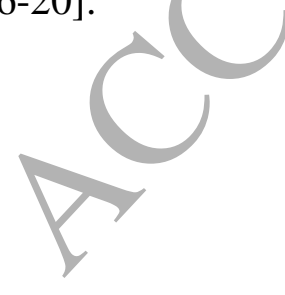




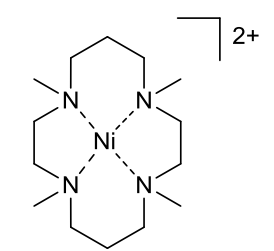

Substituted Ni(cyclam)

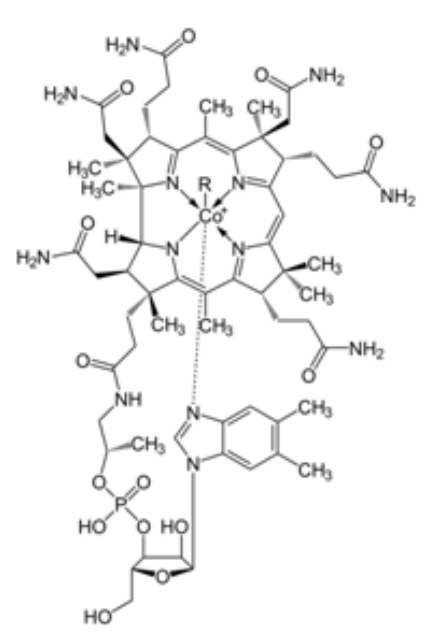

Vitamin B12

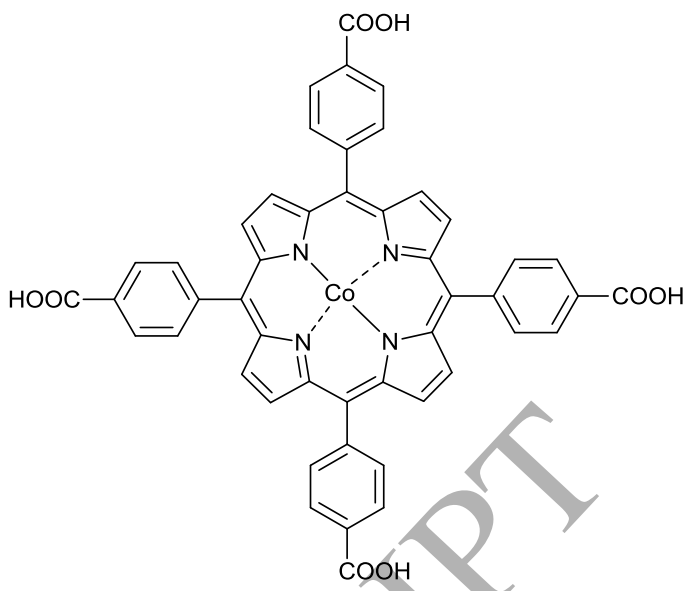

Substituted tetraphenylporphyrin cobalt

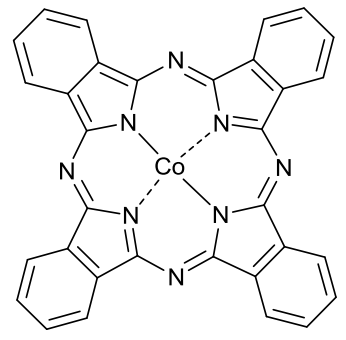

Co-phthalocyanine
Co-salen

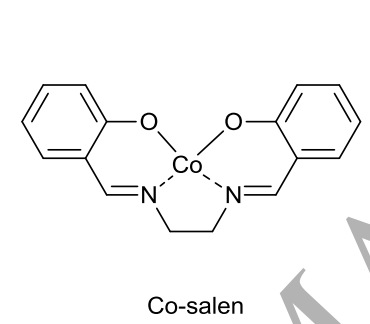

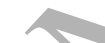

Scheme 1: Examples of catalysts used for reductive dehalogenation in aqueous medium.

A lot of work has also been carried out around vitamin B12 (Cob(I)alamin) $[12,21]$ and its biomimetic models such as substituted tetraphenylporphyrin cobalt [22] and metal phthalocyanines [23]. The complexes were able to reduce tetrachloroethene and trichloroethene [24] as well as polychlorinated biphenyls [25]. Other Co complexes such as polypyridyl $\mathrm{Co}(\mathrm{I})$ complexes and $\mathrm{Co}(\mathrm{I})$ salen (or $\mathrm{Ni}(\mathrm{I})$ salen) have also shown good catalytic activity towards the reduction of carbon-chlorine bonds [26-29]. It is worth noting that even if the removal of halogenated atoms is known to improve the biodegradability of pollutants, their biorecalcitrance can also be due to the presence of several functional groups in their structure. For example, when alachlor is reduced into its dechlorinated derivative, deschloroalachlor, the solution still exhibits a non-biodegradable behavior, preventing the direct implementation of a subsequent biological treatment [26]. Acetanilide and methoxyl groups have been suspected to be linked to the biorecalcitrance of the molecule.

The reduction of nitro groups into amine has also proven its efficiency to improve the biodegradability of nitromethane [30] and nitroimidazole drugs [31-33]. Nitroaromatic compounds are known to give hydroxylamine derivatives by a four-electron reduction process in aqueous medium (Scheme 2). Further two-electron reduction of hydroxylamine in amine can be generally performed at more negative potential in strong acidic medium. Interestingly, titanocene dichloride allows the six-electron reduction of the nitro group in the amino derivative, without the formation of hydroxylamine intermediate. 


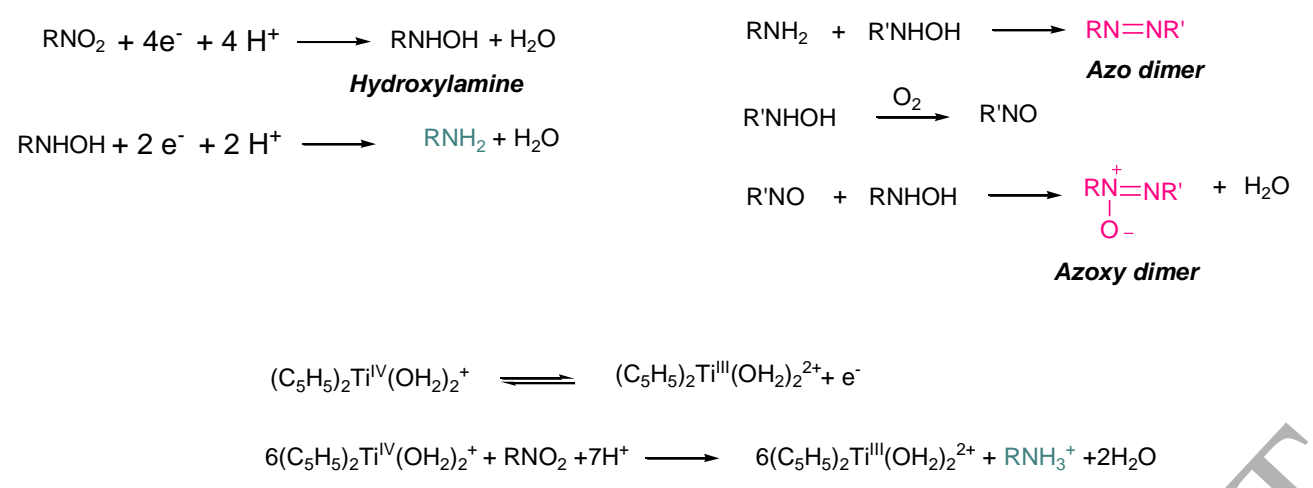

Scheme 2: Direct and catalytic reduction of nitro compounds

This catalytic electrochemical reaction can be particularly interesting as pre-treatment since hydroxylamine is not stable and gives rise to the formation of azo and azoxy dimers, which can decrease the biodegradability of the solution. Thus, it has been shown that the catalytic reduction of metronidazole with titanocene dichloride combined to a/biological treatment improves the mineralization yield by about $14 \%$ compared with a coupling process using direct reduction as pre-treatment [32].

\section{Electrocatalysis}

Metal electrodes have been widely studied for their catalytic activity towards the reduction of carbon-halogen bonds [13, 34]. Thus, electrocatalytic hydrogenolysis (ECH) is a highlyefficient method for the dechlorination of chlorophenols. Pd is usually used as catalyst in the ECH process owning to its strong ability to absorption of hydrogen. To reduce the cost of the electrode and increase its surface area, a thin layer of $\mathrm{Pd}$ is often chemically or electrochemically deposited on a porous substrate. Ni foam has been widely used as electrode support owning to its remarkable stability in many media, with sometimes additives such as reduced graphene oxide, polypyrrole or nanosized titanium nitride to improve the catalytic performances of the modified electrodes [35-39]. Porous carbon such as carbon felt and reticulated vitreous carbon has also been used as Pd support owning to its non-toxicity and high adsorption capacity (Figure 1) [40-43].

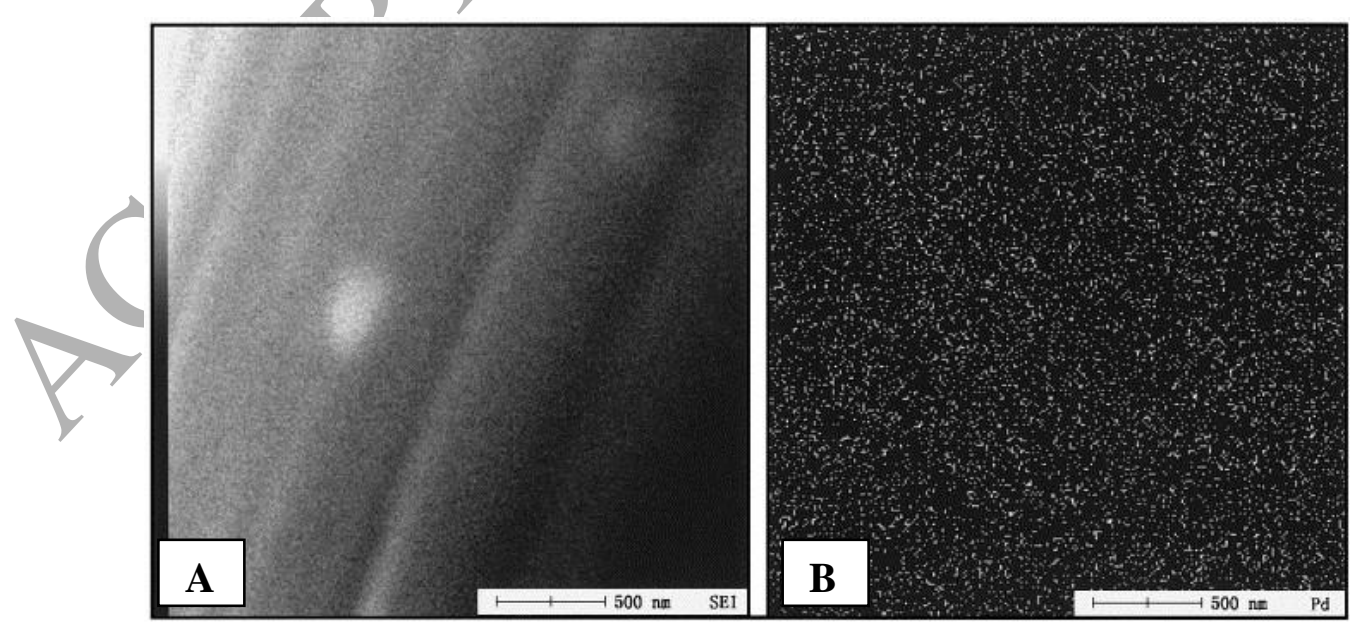

Figure 1: Scanning electron microscopy (SEM) images of palladium-loaded carbon felt: (A) the secondary electron image (SEI) of the felt surface and (B) the mapping of supported palladium from the energy-dispersive X-ray analysis (EDAX). (Reproduced with modification from [41].) 
Thus, Pd-loaded carbon electrodes have shown good catalytic ability for the dehalogenation reaction of pentachlorophenol and other chlorophenyl derivatives. Although Pd exhibits a high activity in hydrodehalogenation reaction, a drawback is its deactivation during the electrochemical process. Several reasons have been evoked to explain its low stability such as halogen poisoning and passivation of the surface [34].

Silver has also proven its high efficiency towards the dehalogenation reaction of pollutants [44]. This property has been attributed to specific interactions of the $\mathrm{C}-\mathrm{Cl}$ bond with $\mathrm{Ag}$ that facilitates the electron transfer [45]. Degradation of environmental pollutants such as polychloromethanes, polychloroethanes, polychloroethylenes and pesticides has been achieved in aqueous medium [46]. Interestingly, dechlorinations of polychlorophenols and other aromatic species have also been reported [46, 47]. Nanostructured particles of silver are particularly interesting owning to their large surface-to-volume ratio, leading to efficient electrode materials with low precious metal loading (Figure 2) [48].
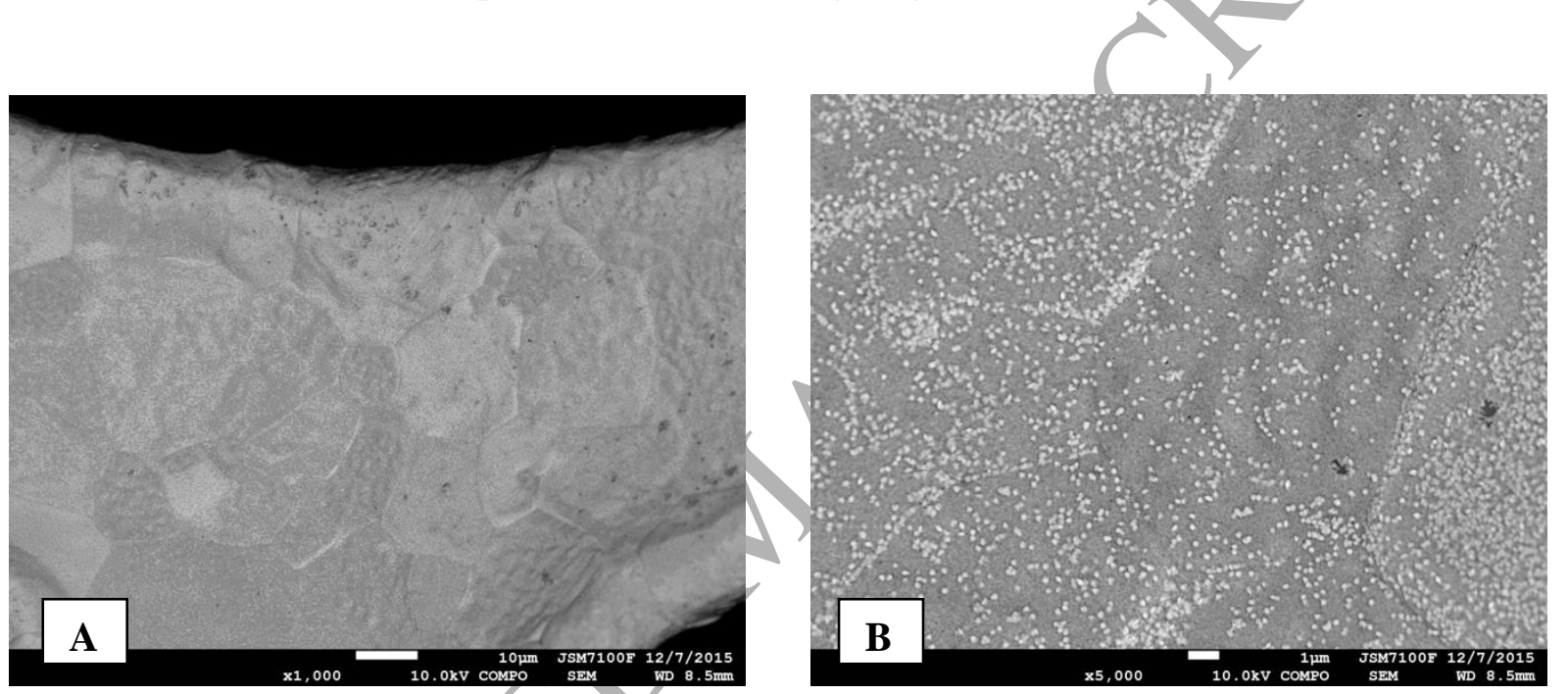

Figure 2: Scanning electron microscopy (SEM) images of Ag-nanoparticules on Ni foams (A $\times 1000, \mathrm{~B} \times 5000)($ Reproduced with modification from [49].)

The deposition of silver on porous substrates can be achieved by electrodeposition and spontaneous deposition through galvanic displacement reactions. Electrodeposition allows a good control of the charge and therefore of the silver loading, whereas spontaneous reaction does not suffer from the problem of the potential repartition inside the volumic electrode. The high adsorption ability of $\mathrm{Ag}$ for pollutants can also be combined with the hydrodehalogenation ability of $\mathrm{Pd}$ through bimetallic materials $(\mathrm{Pd} / \mathrm{Ag})$, allowing for example the dechlorination of 2,4-dichlorophenoxyacetic acid [50,51]. This synergetic effect is a nice example of the interest of multi-metal catalysts.

Although catalytic reactions aiming to improve the biodegradability of a molecule by the transformation of a targeted functional group often involved electrochemical reductions, it is worth noting that electrochemical oxidations can also be investigated. Thus, catalytic oxidation on $\mathrm{Ni}$ graphite felt electrodes has been performed to improve the biodegradability of a solution of tetracycline, a polyketide antibiotic $[52,53]$. In basic medium $(\mathrm{pH}>12), \mathrm{Ni}$ electrodes exhibit a quasi-reversible system, around $0.38 \mathrm{~V} / \mathrm{SCE}$ at $\mathrm{pH}=13$, corresponding to the couple nickel hydroxide/nickel oxyhydroxide $\left(\mathrm{Ni}^{\mathrm{II}}(\mathrm{OH})_{2} / \mathrm{Ni}^{\mathrm{III}} \mathrm{OOH}\right)$. The oxidation of tetracycline catalyzed by $\mathrm{NiOOH}$ led to its complete degradation with a low mineralization level. The molecule lost all its nitrogen content, showing that the two $\mathrm{C}-\mathrm{N}$ bonds were broken. 
A subsequent biological treatment performed on the electrolyzed solution highlighted a total mineralization yield of $69 \%$ for the combined process after 11.5 days of culture.

\section{Concluding remarks}

Catalytic electrochemical oxidations and reductions are particularly relevant to achieve selective and well-controlled transformations of persistent compounds, allowing the increase of their biodegradability. The treatment can be oriented towards the removal of specific functional groups that are suspected to be responsible for their biorecalcitrance. Both molecular catalysts and metals have been investigated. The first ones are particularly attractive since it is possible to play on their molecular structure to achieve very selective reactions, although a special effort will have to be made on the regeneration of the modified electrodes. The intrinsic catalytic properties of the second ones can be exploited too. Indeed, the variety of composite metallic electrodes and nanostructured materials also led to the development of very efficient electrodes, showing generally very good stability. The scope of catalytic electrochemical reactions is still far from fully explored for the remediation of persistent organic pollutants. Coupling processes open up a vast array of potentially useful selective electrochemical pre-treatments. 


\section{References and recommended reading}

[1] H. Loonen, F. Lindgren, B. Hansen, W. Karcher, J. Niemela, K. Hiromatsu, M. Takatsuki, W. Peijnenburg, E. Rorije, J. Struijs, Prediction of biodegradability from chemical structure: modeling of ready biodegradation test data, Environ. Toxicol. Chem., 18 (1999) 1763-1768.

[2] M. Assassi, F. Fourcade, F. Geneste, D. Floner, R. Maachi, A. Amrane, Combined electrochemical and biological treatment for pesticide degradation-application to phosmet, Int. J. Environ. Res., 5 (2011) 41-46.

[3] J.M. Fontmorin, J. Siguie, F. Fourcade, F. Geneste, D. Floner, I. Soutrel, A. Amrane, Combined electrochemical treatment/biological process for the removal of a commercial herbicide solution, U46D, Sep. Purif. Technol., 132 (2014) 704-711.

[4] J.-M. Fontmorin, F. Fourcade, F. Geneste, D. Floner, S. Huguet, A. Amrane, Combined process for 2,4-Dichlorophenoxyacetic acid treatment-Coupling of an electrochemical system with a biological treatment, Biochem. Eng. J., 70 (2013) 17-22.

[5] J.-M. Fontmorin, S. Huguet, F. Fourcade, F. Geneste, D. Floner, A. Amrane, Electrochemical oxidation of 2,4-dichlorophenoxyacetic acid: Analysis of by-products and improvement of the biodegradability, Chem. Eng. J., 195-196 (2012) 208-217.

[6] N.A. Salles, F. Fourcade, F. Geneste, D. Floner, A. Amrane, Relevance of an electrochemical process prior to a biological treatment for the removal of an organophosphorous pesticide, phosmet, J. Hazard. Mater., 181 (2010) 617-623.

[7] I. Saidi, I. Soutrel, F. Fourcade, A. Amrane, D. Floner, N. Bellakhal, F. Geneste, Flow electrolysis on high surface electrode for biodegradability enhancement of sulfamethazine solutions, J. Electroanal. Chem., 707 (2013) 122-128.

[8] I. Saidi, F. Fourcade, D. Floner, I. Soutrel, N. Bellakhal, A. Amrane, F. Geneste, Sulfamethazine removal by means of a combined process coupling an oxidation pretreatment and activated sludge culture - preliminary results, Envíron. Technol., 38 (2017) 2684-2690.

[9] J.-M. Fontmorin, F. Fourcade, F. Geneste, I. Soutrel, D. Floner, A. Amrane, Direct electrochemical oxidation of a pesticide, 2,4-dichlorophenoxyacetic acid, at the surface of a graphite felt electrode: Biodegradability improvement, C. R. Chim., 18 (2015) 32-38.

**[10] R. Francke, R.D. Little, Redox catalysis in organic electrosynthesis: basic principles and recent developments, Chem. Soc. Rev., 43 (2014) 2492-2521.

A recent and complete review on indirect electrolysis

[11] M. Vallejo, M.F. San Roman, I. Ortiz, Quantitative Assessment of the Formation of Polychlorinated Derivatives, PCDD/Fs, in the Electrochemical Oxidation of 2-Chlorophenol As Function of the Electrolyte Type, Environ. Sci. Technol., 47 (2013) 12400-12408.

[12] S. Kliegman, K. McNeill, Dechlorination of chloroethylenes by cob(I)alamin and cobalamin model complexes, Dalton Trans., (2008) 4191-4201.

**[13] D.G. Peters, C.M. McGuire, E.M. Pasciak, A.A. Peverly, L.M. Strawsine, E.R. Wagoner, J.T. Barnes, Electrochemical dehalogenation of organic pollutants, J. Mex. Chem. Soc., 58 (2014) 287-302.

An exhaustive review on the dehalogenation of organic pollutants

[14] H. Lund, O. Hammerich, Organic electrochemistry, M. Dekker, Inc., New York, 2001. *[15] E.T. Martin, C.M. McGuire, M.S. Mubarak, D.G. Peters, Electroreductive Remediation of Halogenated Environmental Pollutants, Chem. Rev., 116 (2016) 15198-15234.

A review on the electroreduction of organic pollutants with a specific part on indirect reduction

[16] E. Dunach, A.P. Esteves, M.J. Medeiros, S. Olivero, Reductive cyclisation of propargyloxy and allyloxy a-bromoester derivatives using environmentally friendly electrochemical methodologies, Green Chem., 8 (2006) 380-385. 
[17] E. Dunach, M.J. Medeiros, S. Olivero, Electrochemical catalytic cyclization reactions using environmentally friendly methodologies, J. Electrochem. Soc., 160 (2013) G3112G3116.

[18] J.M. Fontmorin, W.Y. He, D. Floner, F. Fourcade, A. Amrane, F. Geneste, Reductive dehalogenation of 1,3-dichloropropane by a [Ni(tetramethylcyclam) $] \mathrm{Br}_{2}-\mathrm{Nafion}$ modified electrode, Electrochim. Acta, 137 (2014) 511-517.

[19] Y. Albo, E. Shandalov, L. Hayoun, I. Zilbermann, E. Maimon, D. Meyerstein, Homogeneous and heterogeneous electrocatalytic reduction of halo-organic compounds by $\left(\mathrm{Ni}^{\mathrm{II}} \mathrm{Li}\right)^{2+}(\mathrm{Li}=$ tetraaza-macrocyclic ligand $)$ in aqueous solutions, Inorg. Chim. Acta, 466 (2017) 502-509.

[20] K.C. Pillai, G. Muthuraman, I.-S. Moon, Electrochemically mediated reduction of epichlorohydrin pollutant by $\mathrm{Ni}(\mathrm{I})$ (hexamethylcyclam) in aqueous media, Electrochim. Acta, 232 (2017) 570-580.

[21] J. Shey, W.A. van der Donk, Mechanistic Studies on the Vitamin B12-Catalyzed Dechlorination of Chlorinated Alkenes, J. Am. Chem. Soc., 122 (2000) 12403-12404.

[22] J.M. Fritsch, K. McNeill, Aqueous reductive dechlorination of chlorinated ethylenes with tetrakis-(4-carboxyphenyl)porphyrin cobalt, Inorg. Chem., 44 (2005) 4852-4861.

[23] M.O. Iwunze, N. Hu, J.F. Rusling, Electrocatalysis in organized assemblies. Part X. Debromination of alkyl vicinal dibromides with neutral metal phthalocyanines in a bicontinuous microemulsion, J. Electroanal. Chem., 333 (1992) 353-361.

[24] G. Glod, U. Brodmann, W. Angst, C. Holliger, R.P. Schwarzenbach, CobalaminMediated Reduction of cis- and trans-Dichloroethene, 1,1-Dichloroethene, and Vinyl Chloride in Homogeneous Aqueous Solution: Reaction Kinetics and Mechanistic Considerations, Environ. Sci. Technol., 31 (1997) 3154-3160.

[25] S.L. Woods, D.J. Trobaugh, K.J. Carter, Polychlorinated Biphenyl Reductive Dechlorination by Vitamin B12s: Thermodynamics and Regiospecificity, Environ. Sci. Technol., 33 (1999) 857-863.

[26] W. He, J.-M. Fontmorin, I. Soutrel, D. Floner, F. Fourcade, A. Amrane, F. Geneste, Reductive dechlorination of a chloroacetanilide herbicide in water by a Co complex-supported catalyst, Mol. Catal., 432 (2017) 8-14.

*[27] W.Y. He, J.M. Fontmorin, P. Hapiot, I. Soutrel, D. Floner, F. Fourcade, A. Amrane, F. Geneste, A new bipyridyl cobalt complex for reductive dechlorination of pesticides, Electrochim. Acta, 207 (2016) 313-320.

Selective dechlorination of alachlor by indirect electrolysis

[28] U. Paramo-Garcio, M. Avila-Rodriguez, M.G. Garcia-Jimenez, S. Gutierrez-Granados, J.G. Ibanez-Cornejo, Electrochemical reduction of hexachlorobenzene in organic and aquoorganic media with Co(II)salen as catalyst, Electroanalysis, 18 (2006) 904-910.

[29] C.M. McGuire, A.M. Hansen, J.A. Karty, D.G. Peters, Catalytic reduction of 4,4'-(2,2,2trichloroethane-1,1-diyl)bis(methoxybenzene) (methoxychlor) with nickel(I) salen electrogenerated at reticulated vitreous carbon cathodes, J. Electroanal. Chem., 772 (2016) 66-72.

[30] M. Sun, D.D. Reible, G.V. Lowry, K.B. Gregory, Effect of Applied Voltage, Initial Concentration, and Natural Organic Matter on Sequential Reduction/Oxidation of Nitrobenzene by Graphite Electrodes, Environ. Sci. Technol., 46 (2012) 6174-6181.

[31] I. Saidi, I. Soutrel, F. Fourcade, A. Amrane, N. Bellakhal, F. Geneste, Electrocatalytic reduction of metronidazole using titanocene/Nafion-modified graphite felt electrode, Electrochim. Acta, 191 (2016) 821-831.

[32] I. Saidi, I. Soutrel, D. Floner, F. Fourcade, N. Bellakhal, A. Amrane, F. Geneste, Indirect electroreduction as pretreatment to enhance biodegradability of metronidazole, J. Hazard. Mater., 278 (2014) 172-179. 
*[33] M. Zaghdoudi, F. Fourcade, I. Soutrel, D. Floner, A. Amrane, H. Maghraoui-Meherzi, F. Geneste, Direct and indirect electrochemical reduction prior to a biological treatment for dimetridazole removal, J. Hazard. Mater., 335 (2017) 10-17.

Improvment of the biodegradability of nitroimidazole antibiotics by the reduction of their nitro group and implementation of a coupling process.

**[34] M. Hu, Y. Liu, Z. Yao, L. Ma, X. Wang, Catalytic reduction for water treatment, Front. Environ. Sci. Eng., 12 (2018) 1-18.

A complete review on electrocatalysis using metallic electrodes.

[35] K. Zhu, S.A. Baig, J. Xu, T. Sheng, X. Xu, Electrochemical reductive dechlorination of 2,4-dichlorophenoxyacetic acid using a palladium/nickel foam electrode, Electrochim. Acta, 69 (2012) 389-396.

[36] Y. Liu, L. Liu, J. Shan, J. Zhang, Electrodeposition of palladium and reduced graphene oxide nanocomposites on foam-nickel electrode for electrocatalytic hydrodechlorination of 4chlorophenol, J. Hazard. Mater., 290 (2015) 1-8.

[37] Z.-R. Sun, H. Ge, X. Hu, Y.-Z. Peng, Preparation of foam-nickel composite electrode and its application to 2,4-dichlorophenol dechlorination in aqueous solution, Sep. Purif. Technol., 72 (2010) 133-139.

[38] C. Sun, Z. Lou, Y. Liu, R. Fu, X. Zhou, Z. Zhang, S.A. Baig, X. Xu, Influence of environmental factors on the electrocatalytic dechlorination of 2,4-dichlorophenoxyacetic acid on nTiN doped Pd/Ni foam electrode, Chem. Eng. J., 281 (2015) 183-191.

[39] Z. Sun, G. Song, R. Du, X. Hu, Modification of a Pd-loaded electrode with a carbon nanotubes-polypyrrole interlayer and its dechlorination performance for 2,3-dichlorophenol, RSC Adv., 7 (2017) 22054-22062.

[40] C. Cui, X. Quan, S. Chen, H. Zhao, Adsorption and electrocatalytic dechlorination of pentachlorophenol on palladium-loaded activated carbon fibers, Sep. Purif. Technol., 47 (2005) 73-79.

[41] A.I. Tsyganok, K. Otsuka, Selective dechlorination of chlorinated phenoxy herbicides in aqueous medium by electrocatalytic reduction over palladium-loaded carbon felt, Appl. Catal., B, 22 (1999) 15-26.

[42] A.I. Tsyganok, I. Yamanaka, K. Otsuka, Dechlorination of chloroaromatics by electrocatalytic reduction over palladium-loaded carbon felt at room temperature, Chemosphere, 39 (1999) 1819-1831.

[43] P. Dabo, A. Cyr, F. Laplante, F. Jean, H. Menard, J. Lessard, Electrocatalytic Dehydrochlorination of Pentachlorophenol to Phenol or Cyclohexanol, Environ. Sci. Technol., 34 (2000) 1265-1268.

[44] S. Ardizzone, G. Cappelletti, L.M. Doubova, P.R. Mussini, S.M. Passeri, S. Rondinini, The role of surface morphology on the electrocatalytic reduction of organic halides on monoand polycrystalline silver, Electrochim. Acta, 48 (2003) 3789-3796.

[45] Y.-F. Huang, D.-Y. Wu, A. Wang, B. Ren, S. Rondinini, Z.-Q. Tian, C. Amatore, Bridging the gap between electrochemical and organometallic activation: benzyl chloride reduction at silver cathodes, J. Am. Chem. Soc., 132 (2010) 17199-17210.

[46] Y. Xu, Y. Zhu, F. Zhao, C.-a. Ma, Electrocatalytic reductive dehalogenation of polyhálogenated phenols in aqueous solution on Ag electrodes, Appl. Catal., A, 324 (2007) 83-86.

[47] C.M. McGuire, D.G. Peters, Electrochemical dechlorination of 4,4'-(2,2,2trichloroethane-1,1-diyl)bis(chlorobenzene) (DDT) at silver cathodes, Electrochim. Acta, 137 (2014) 423-430.

[48] E. Verlato, W. He, A. Amrane, S. Barison, D. Floner, F. Fourcade, F. Geneste, M. Musiani, R. Seraglia, Preparation of Silver-Modified Nickel Foams by Galvanic Displacement 
and Their Use as Cathodes for the Reductive Dechlorination of Herbicides, ChemElectroChem, 3 (2016) 2084-2092.

[49] W. He, Y. Lou, E. Verlato, I. Soutrel, D. Floner, F. Fourcade, A. Amrane, M. Musiani, F. Geneste, Reductive dehalogenation of a chloroacetanilide herbicide in a flow electrochemical cell fitted with Ag-modified Ni foams, J. Chem. Technol. Biotechnol., 93 (2018) 1572-1578.

[50] Y.H. Xu, Q.Q. Cai, H.X. Ma, Y. He, H. Zhang, C.A. Ma, Optimisation of electrocatalytic dechlorination of 2,4-dichlorophenoxyacetic acid on a roughened silver-palladium cathode, Electrochim. Acta, 96 (2013) 90-96.

[51] C.-a. Ma, H. Ma, Y.-h. Xu, Y.-q. Chu, F.-m. Zhao, The roughened silver-palladium cathode for electrocatalytic reductive dechlorination of 2,4-dichlorophenoxyacetic acid, Electrochem. Commun., 11 (2009) 2133-2136.

[52] D. Belkheiri, F. Fourcade, F. Geneste, D. Floner, H. Ait-Amar, A. Amrane, Feasibility of an electrochemical pre-treatment prior to a biological treatment for tetracycline removal, Sep. Purif. Technol., 83 (2012) 151-156.

[53] D. Belkheiri, F. Fourcade, F. Geneste, D. Floner, H. Ait-Amar, A. Amrane, Combined process for removal of tetracycline antibiotic - Coupling pre-treatment with a nickel-modified graphite felt electrode and a biological treatment, Int. Biodeterior. Biodegrad., 103 (2015) 147-153. 


\section{Graphical_abstract}
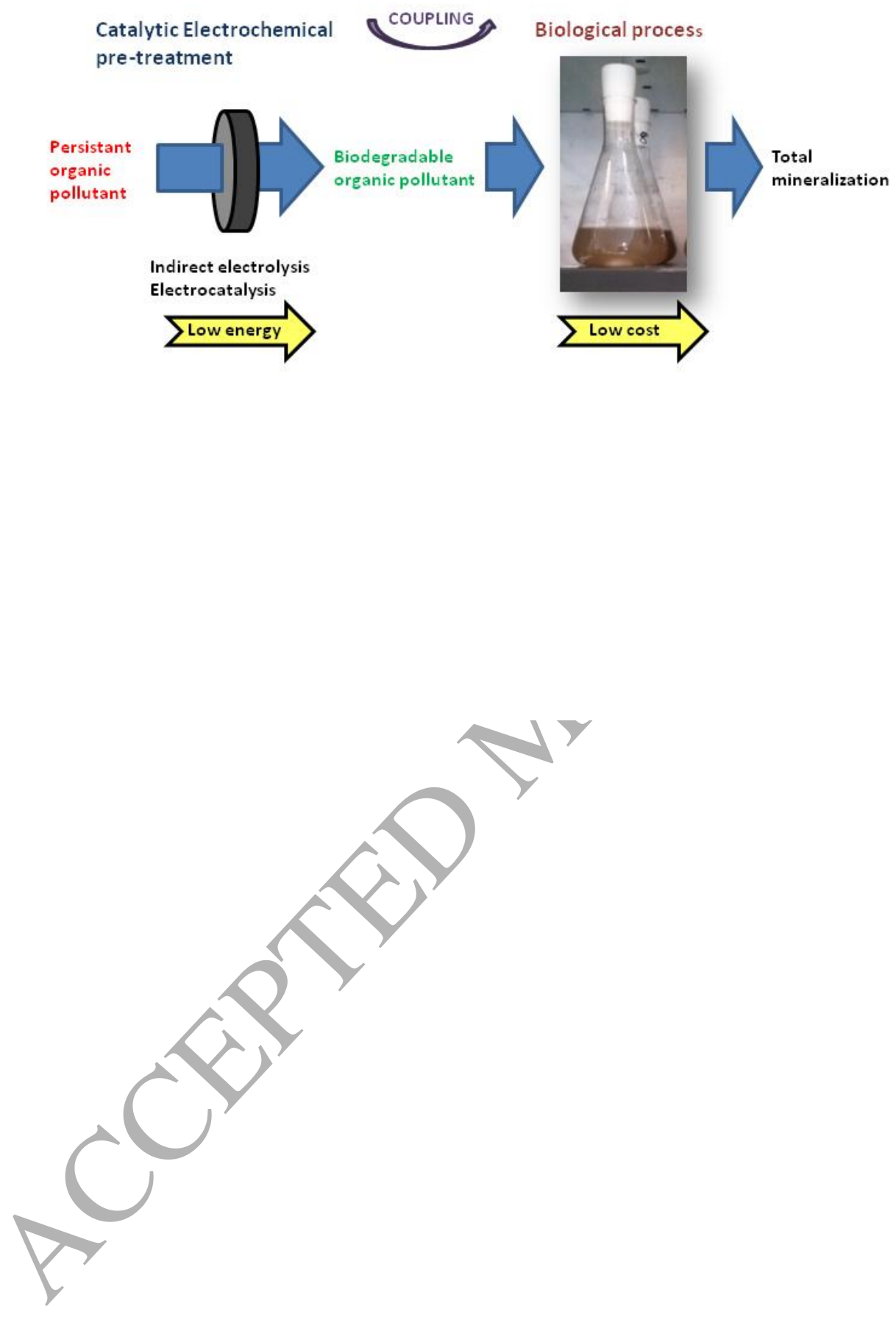